\title{
Fibrinolytic Drug Therapy in the Management of Intravascular Thrombosis, Especially Acute Myocardial Infarction - A Review
}

\author{
*Vivek Lal \\ Professor of Pharmacology \& Chief Academic Officer, American International Medical University, West Indies
}

Submission: March 03, 2017; Published: March 27, 2017

*Corresponding author: Vivek Lal, Department of Pharmacology, American International Medical University, Beausejour Road, Gros Islet, St Lucia, West Indies, Tel: +17584877397; Email: ltcolvivek@gmail.com

\begin{abstract}
Intravascular thrombosis in the form of acute myocardial infarction, acute ischemic stroke etc has become a significant public health problem of late. There are numerous predisposing factors which contribute to the pathogenesis of this dreaded clinical condition. Appropriate and timely initiation of treatment in acute medical emergencies like ST Elevation Myocardial Infarction (STEMI) and Acute Ischemic Stroke (AIS) is mandatory to save lives and minimize morbidity. The use of thrombolytic drugs can be life saving if instituted within an hour of the onset of symptoms of STEMI, so also as early as possible in AIS. There is a range of available thrombolytic drugs, and at times it becomes difficult to make a choice between them, due to differences in cost, efficacy and adverse effects. This review article is intended to highlight the salient features of all available fibrinolytic drugs, so as to facilitate the choice for their use amongst the cardiologists as well as the patients and their families. In addition, some promising new drugs have also been discussed, which may replace the existing ones if they are found more efficacious and devoid of the common adverse effects.
\end{abstract}

Keywords: Thrombolytic drugs; Thrombolysis; Fibrinolytic drugs; Intravascular thrombosis; Reperfusion

Abbreviations: IHD: Ischemic Heart Disease; VTE: Venous Thrombo-Embolism; PPCI: Primary Percutaneous Coronary Intervention; STEMI: ST Elevation Myocardial Infarction; tPA: Tissue Plasminogen Activator; Stk: Streptokinase; rt-PA: Recombinant Tissue-Plasminogen Activator; u-PA: Urokinase Plasminogen Activator; TAFIa: Inhibitors of Active Thrombin Activatable Fibrinolysis Inhibitor

\section{Introduction}

Intravascular thrombosis has become a significant health problem in the current times. It manifests predominantly as Ischemic Heart Disease (IHD) (Acute Myocardial Infarction AMI), ischemic stroke and venous thrombo-embolism (VTE). In a statistical study completed in 2010, it was found that ischemic heart disease led to 7.0 million deaths annually all over the world, while ischemic stroke caused 5.9 million deaths [1]. Since 1990, there has been a $35 \%$ and $25 \%$ increase in the mortality from IHD and ischemic stroke respectively [2]. These are alarming statistics. The common precipitating factors for intravascular thrombotic events are prolonged immobility, trauma, surgery, acute medical illness, increasing global prevalence of obesity, atherosclerosis, glucose intolerance and dyslipidemias [3]. In addition, certain genetic factors also contribute towards elevated levels of certain coagulation factors (Factor VII, PAI-1) and fibrinogen, which significantly contribute towards this ever increasing incidence and prevalence of thrombotic episodes [4]. Thus, it is imperative that the threat of intravascular thrombosis be adequately countered by appropriate drug therapy as well as surgical interventions.

Most of the intravascular thrombotic events like VTE can be managed by supportive care and initiation of anti-coagulant therapy with heparin, LMW heparin or oral anti-coagulants [5]. Many new platelet aggregation inhibitors may be added to these regiments. However, acute myocardial infarction and ischemic stroke are medical emergencies which may need major or minor surgical intervention in addition to drug therapy [6-8]. The issue of thrombolysis vs Primary Percutaneous Coronary Intervention (PPCI) and stenting in the management of acute ST Elevation Myocardial Infarction (STEMI) is a topic 
of hot debate, but it has been universally accepted that an early initiation of thrombolytic therapy (within 12 hours of the onset of symptoms), especially with fibrin specific thrombolytic drugs like TNK-tPA (Tenecteplase) can eliminate the immediate need of a Primary cardiac intervention [9]. Indeed, pre-hospital thrombolysis in STEMI has been a topic of intense research and studies all over the world, with the intention of minimizing cardiac muscle damage as well as the need of a Primary PCI and stenting, depending on individual patient requirements $[10,11]$. The application of telemedicine has been strongly mooted in pre-hospital thrombolysis, and many hospitals and institutions are actively supporting such programs [12]. This article is intended to discuss the available thrombolytic drugs and to recommend the best possible options to achieve reperfusion and minimization of tissue injury after intravascular thrombosis, especially in STEMI and ischemic stroke.

\section{Discussion}

Till early $20^{\text {th }}$ century, "heart attacks" were believed to be "invariably fatal!" However, it was seen that few victims of an acute myocardial infarction did survive the first episode. It was only in 1933 that the first thrombolytic drug, Streptokinase, was discovered serendipitously by William Smith Tillett, who tried it for acute MI in the year 1958 after its initial applications in the management of fibrinous pleural exudates, hemothorax and tuberculous meningitis [13]. In spite of being a revolutionary discovery in the curative management of AMI, use of streptokinase was always associated with significant adverse effects, especially hypersensitivity reactions. A similar drug, Urokinase, which was discovered in 1947 [14], was also not found to be very suitable due to its non-selectivity for clot bound fibrinogen. We will now discuss the basic physiology of thrombolysis, followed by all the available pharmacological options to achieve the same, with their specific merits \& demerits. Suggested new advances will also be discussed.

\section{Basic physiology of fibrinolysis}

Physiological hemostasis involves the formation of a platelet plug at the site of injury which is further reinforced by fibrin deposition to form a thrombus (clot). Once the tissue and vascular repair is completed, the fibrinolytic system is activated to dissolve this clot by a proteolytic digestion of fibrin. This is achieved by activation of plasmin from its precursor plasminogen, by tissue plasminogen activator (tPA), released primarily from vascular endothelium. Plasminogen is found free in the plasma as well as bound to fibrin. Fibrin bound plasminogen is selectively activated by tPA. Plasmin is the enzyme which digests fibrin to disintegrate a thrombus [15]. To maintain optimal fibrinolysis and to exclude a systemic lytic state, any plasmin that leaks out of a clot is immediately inactivated by circulating $\alpha_{2}$ antiplasmin. The tPA in turn can also be inactivated by Plasminogen Activator Inhibitors-1 and 2 (PAI-1, PAI-2) released from the vascular endothelium. If $\alpha_{2}$ antiplasmin and PAI-1\&2 are overwhelmed by pharmacological fibrinolysis (administration of thrombolytic drugs), a systemic lytic state is possible in the form of varying degrees of hemorrhage [15].

\section{Available thrombolytic agents}

A. Streptokinase (Stk): It is the first thrombolytic drug to be used clinically. It was obtained from $\beta$-hemolytic group-C streptococci. Streptokinase combines with circulating plasminogen to form an activator complex which generates plasmin from other plasminogen molecules [16]. Since Stk is non-fibrin specific, it depletes circulating plasminogen and predisposes to a bleeding state. Its efficacy in obtaining reperfusion in occluded coronary arteries is controversial, with no studies confirming the superiority of other drugs. However, the propensity to cause severe adverse reactions like hypersensitivity reactions, anaphylaxis and increased incidence of hemorrhage [16], Stk is sparingly used now except where low cost therapy is needed.

B. Urokinase: An enzyme initially isolated from human urine and later prepared from kidney culture cells, Urokinase is a direct plasminogen activator which is non-antigenic and thus does not produce hypersensitivity reactions. It does, however, cause pyrexia. Except for patients for whom Stk was used earlier, Urokinase finds very limited clinical use [14,17].

C. Alteplase (Recombinant tissue-Plasminogen activator - rt-PA): It is a moderately fibrin-bound specific plasminogen activator produced by recombinant DNA technology from human tissue cultures. It does affect the circulating fibrinogen to the tune of $50 \%$, and is rapidly inactivated by PAI-1. It has to be administered initially as a bolus dose followed by a slow intravenous infusion, due to a very short half life, with additional heparin most of the times. It is well tolerated and is nonantigenic. Increased incidence of hemorrhage is a significant adverse effect. It is increasingly being used in the treatment of acute ischemic stroke rather than acute STEMI [18].

D. Reteplase (rt-PA): The only advantage over Alteplase is longer duration of action and a bolus dose administration, eliminating the need of an intravenous infusion. However, it needs two bolus doses. Its specificity for fibrin bound plasminogen is similar to alteplase [19].

E. Tenecteplase (TNK-tPA) (TNK-ase): It's a genetically engineered mutant of tissue plasminogen activator with a longer half life due to a reduced plasma clearance, resistance to inhibition by PAI-1 and a higher selectivity to fibrin bound plasminogen. It also has an added selectivity to platelet rich thrombi. Another distinct advantage is its administration by a single bolus intravenous injection [20]. In spite of claims to the contrary, there is no proven superiority over alteplase in the incidence of intracerebral hemorrhage. A recent study, though, claims some superiority of Tenecteplase over alteplase in the 
incidence of major bleeding episodes [21]. There might even be a lesser incidence of non-cerebral complications [22].

F. Lanoteplase: Like Tenecteplase, Lanoteplase is also a rationally designed recombinant tissue plasminogen activator, administered as a single bolus dose. Few clinical trials have shown its superiority over alteplase in restoring perfusion in STEMI, so also in lesser number of hemorrhagic adverse effects $[23,24]$. However, there are no evident studies comparing tenecteplase and lanoteplase in their efficacy or side effects.

G. Saruplase: Saruplase is a unglycosylated human-type high molecular weight single-chain urokinase-type plasminogen activator, administered as an initial bolus dose followed by an intravenous infusion. However, it was found to be more effective when administered concurrently with aspirin and heparin [25]. As compared to Streptokinase, it is claimed to be superior due to a higher patency rate, earlier reperfusion, less bleeding complications and a lesser disturbance of hemostasis [26]. However, it remains inferior to the single bolus drugs like tenecteplase.

H. Staphylokinase: Obtained from the bacteria Staphylococcus aureus, Staphylokinase is another plasminogen activator which was introduced after streptokinase. It specifically stimulates thrombolysis of both erythrocyte-rich and plateletrich thrombi. It lacks fibrin binding or specificity and has no effect on thrombin inhibition [27]. It can be administered in a single bolus dose but its efficacy and safety in comparison with single bolus drugs like tenecteplase remains to be ascertained.

\section{Newer thrombolytic drugs}

I. Alfimeprase: It's a recombinant congener of Fibrolase, which in itself is a zinc metalloprotease isolated from the venom of Southern Copperhead snake (Agkistrodon contortrix contortrix). It is unique in the sense that instead of activating plasminogen, it directly degrades the $\alpha$-chains of fibrin and fibrinogen. It is not inhibited by PAI-1. The incidence of bleeding complications might be lesser as compared to other agents [28]. Neutralization by $\alpha_{2}$-macroglobulin and the need to deliver this drug directly into the thrombus has limited the clinical utility of alfimeprase [29].

II. Desmoteplase: This is a recombinant analog of a plasminogen activator originally obtained from the saliva of a vampire bat (Desmodus rotundus). It is quite similar to t-PA and has greater fibrin specificity, thereby producing lesser bleeding complications. It thus activates fibrin bound plasminogen and leads to clot lysis after a single bolus dose [29]. However, the exact status of this drug in the therapy of intravascular thrombosis, especially acute ischemic stroke, is still under evaluation [30].

III. Plasmin: Direct delivery of plasmin into a thrombus via a catheter has the potential to cause rapid degradation of that clot. $\alpha_{2}$-antiplasmin will rapidly inactivate any excess plasmin which is not bound to fibrin. This eliminates the possibility of a systemic lytic state. Many preparations of plasmin have been tried in different clinical trials for the treatment of AIS. However, a new form of plasma derived plasmin is currently under evaluation for the treatment of AIS as well as peripheral intravascular thrombosis [29].

\section{New drugs under evaluation}

a) Inhibitors of Type-1 Plasminogen Activator Inhibitor (PAI-1 Inhibitors): PAI-1 is a major physiological inhibitor of tissue plasminogen activator ( $\mathrm{t}-\mathrm{PA}$ ) as well as urokinase plasminogen activator (u-PA). Thus, it becomes a prospective target for drugs which can block its activity, thereby potentiating the actions of t-PA \& u-PA. New drugs being evaluated are expected to decrease PAI-1 gene expression and / or reduce its activity directly, thereby increasing the action of t-PA. Many such proteins have been identified, but their efficacy in vivo remains to be evaluated [29].

b) TAFIa Inhibitors (Inhibitors of active Thrombin Activatable Fibrinolysis Inhibitor) (Carboxypeptidase-U Inhibitors): Fibrinolysis is prevented by TAFIa by cleavage of carboxy terminal lysine residues from fibrin, rendering it incapable of binding with plasminogen or plasmin. TAFIa directed antibodies, nanontibodies and other direct inhibitors are being evaluated for in vivo thrombolysis potentiation activity [29].

c) Factor XIIIa inhibitors: A thrombus is stabilized further by cross linking of the fibrin polymer, which is achieved by thrombin activated factor XIII, or factor XIIIa. Thus, factor XIIIa cross links the $\alpha$ - and $\gamma$-chains of fibrinogen to form $\alpha$-polymers and $\gamma$-dimers. This stable thrombus is more refractory to thrombolytic action by plasmin. Inhibition of factor XIIIa, therefore, can be a promising method of making a thrombus more susceptible to lysis. Two potential drugs need further evaluation in humans in this regards. The first one, called Tridegin, is a peptide obtained from Haementeria ghilianii, the giant Amazonian leech. It is a specific inhibitor of factor XIIIa, which can enhance fibrinolysis in vitro if added before the stabilization of the thrombus (polymerization of fibrinogen). The other drug, Destabilase, is another leech enzyme which hydrolyzes or degrades these cross links, thereby having the potential of reversing XIIIa mediated fibrin cross-linking [29].

d) Plasminogen variant V10153: A variant form of plasminogen, coded as V10153, is under evaluation as a thrombolytic agent. The distinguishing feature of this agent is that instead of getting activated to plasmin by plasminogen activators, it gets activated by fibrin bound thrombin due to a modification in the molecule which replaces the plasminogen activator cleavage site with a thrombin cleavage site [29,31]. In a clinical study, this variant was found to have achieved a $100 \%$ reperfusion in an infarct affected artery [32] (Table 1). 
Table 1: Distinguishing features of some commonly used thrombolytic drugs.

\begin{tabular}{|c|c|c|c|c|c|}
\hline Drug & Plasma $t_{1 / 2}$ (Min) & Fibrin specificity & $\begin{array}{c}\text { Plasminogen } \\
\text { activation }\end{array}$ & Antigenicity & Dose \\
\hline Streptokinase & $23-29$ & Nil & Indirect & ++ & 1.5 MIU/60 mins \\
\hline Alteplase & $4-8$ & ++ & Direct & Nil & $100 \mathrm{mg} / 90 \mathrm{mins}$ \\
\hline Reteplase & 15 & + & Direct & Nil & $2 \times 10$ IU boluses 30 mins apart \\
\hline Tenecteplase & 20 & +++ & Direct & Nil & $0.5 \mathrm{mg} / \mathrm{kg}$ bolus \\
\hline Lanoteplase & 23 & + & Direct & Nil & $120 \mathrm{IU} / \mathrm{kg}$ bolus \\
\hline Saruplase & 9 & \pm & Direct & Nil & $80 \mathrm{mg} / 60 \mathrm{mins}$ \\
\hline Staphylokinase & 6 & ++++ & Indirect & + & $20-30 \mathrm{mg} / 30 \mathrm{~min}$ \\
\hline
\end{tabular}

\section{Conclusion}

Since the advent of Streptokinase in 1933, there has been a constant search for new thrombolytic drugs with the simple objectives of improved efficacy, early reperfusion, avoidance of reperfusion injury, efficacy even after delayed initiation of treatment, convenient (single bolus) administration, lack of antigenicity, fibrin selectivity, immunity to inactivation by PAI-1 and minimal adverse effects like increased bleeding tendencies, especially the likelihood of intra-cerebral hemorrhage. Many drugs have been identified since then, but a perfect fibrinolytic agent still remains a dream! The 'nearest to perfection' drug is tenecteplase, due to its molecular modification to suit most of the requirements given above. Many new drugs are also being investigated, more so due to a major limitation of these drugs being ineffective after a lapse of 90 minutes of the onset of symptoms in STEMI, so also the likelihood of a systemic lytic state. This quest will continue till a perfect thrombolytic is found which can completely eliminate the need of Primary PCI, angioplasty and stenting, with minimal and inconsequential adverse effects. Ongoing investigations may indeed yield such a drug in the days to come.

\section{References}

1. ISTH Steering Committee for World Thrombosis Day (2014) Thrombosis: a major contributor to the Global Disease Burden. J Thromb hemost 12(10): 1580-1590.

2. Lozano R, Naghavi M, Foreman K, Lim S, Shibuya K, et al. (2012) Global and regional mortality from 235 causes of death for 20 age groups in 1990 and 2010: a systematic analysis for the Global Burden of Disease Study 2010. Lancet 380(9859): 2095-2128.

3. Lowe GD (2004) Venous and arterial thrombosis: epidemiology and risk factors at various ages. Maturitas 47(4): 259-263.

4. F Zito, SE Humphries (2000) Epidemiology of arterial thrombosis; gene-environment interaction, risk factors for coronary heart disease. Arch Hellenic Med 17(A): 35-43.

5. Piran S, Schulman S (2016) Management of venous thromboembolism: an update. Thromb J 14(1):23: 107-115.

6. Reddy K, Khaliq A, Henning RJ (2015) Recent advances in the diagnosis and treatment of acute myocardial infarction. World J Cardiol 7(5): 243-276.

7. Italo Linfante, Nabil M Akkawi (2006) Advances in treatment of acute ischemic stroke. Curr Neurol Neurosci Rep 6(1): 28-32.
8. Widimsky P, Coram R, Abou-Chebl A (2014) Reperfusion therapy of acute ischemic stroke and acute myocardial infarction: similarities and differences. Eur Heart J 35(3): 147-155.

9. Hilleman DE, Tsikouris JP, Seals AA, Marmur JD (2007) Fibrinolytic agents for the management of ST-segment elevation myocardial infarction. Pharmacotherapy 27(11): 1558-1570.

10. Vaishnav A, Vaishnav A, Khandekar S, Vaishnav S (2011) Pre-hospital thrombolysis. J Assoc Physicians India 59: 14-18.

11. Paul Kelly (2003) Thrombolysis in the pre-hospital setting. British Journal of Cardiology 10(5).

12. Amadi-Obi A, Gilligan P, Owens N, O'Donnell C (2014) Telemedicine in pre-hospital care: a review of telemedicine applications in the prehospital environment. Int J Emerg Med 7:29.

13. Sikri N, Bardia A (2007) A history of Streptokinase use in Acute Myocardial Infarction. Tex Heart Inst J 34(3): 318-327.

14. Arthur A Sasahara (1998) Urokinase: Past, present and future. Techniques in Vascular and Interventional Radiology 1(4): 170-178.

15.Zehnder JL (2015) Drugs used in Disorders of Coagulation. Basic \& Clinical Pharmacology. (13 ${ }^{\text {th }}$ edn), In: Katzung BG \& Trevor AJ (Eds.), McGraw Hill, USA, pp.587.

16. Brogden RN, Speight TM, Avery GS (1973) Streptokinase: a review of its clinical pharmacology, mechanism of action and therapeutic uses. Drugs 5(5): 357-445.

17. Otaal PS, Talwar KK (2009) Limitations of currently available thrombolytic therapy. Indian Heart J 61(5): 470-475.

18. Doggrell SA (2001) Alteplase: descendancy in myocardial infarction, ascendancy in stoke. Expert opin Investig drugs 10(11): 2013-2029.

19. Simpson D, Siddiqui MA, Scott LJ, Hilleman DE (2006) Reteplase: A review of its use in the management of thrombotic occlusive disorders. Am J Cardiovasc Drugs 6(4): 265-285.

20. M Giovanni, Vagnarelli F, Calabrese D, Semprini F, Nanni S, et al. (2009) Review of Tenecteplase (TNK-ase) in the treatment of acute myocardial infarction. Vasc Health Risk Manag 5(1): 249-256.

21. Guillermin A, Yan DJ, Perrier A, Marti C (2016) Safety and efficacy of tenecteplase versus alteplase in acute coronary syndrome: a systematic review and meta analysis of randomized trials. Arch Med Sci 12(6): 1181-1187.

22. Davydov L, Cheng JW (2001) Tenecteplase : a review. Clin Ther 23(7): 982-997.

23. Bhana M, Spencer CM (2000) Lanoteplase. Biodrugs 13(3): 217-224.

24. Kostis JB, Dockens RC, Thadani U, Bethala V, Pepine C, et al. (2002) Comparison of pharmacokinetics of lanoteplase and alteplase during acute myocardial infarction. Clin Pharmacokinet 41(6): 445-452. 
25. Vermeer F, Bosl I, Meyer J, Bar F, Charbonnier B, et al. (1999) Saruplase is a safe and effective thrombolytic agent; observations in 1698 patients: results of the PASS study. Practical applications of Saruplase study. J Thromb Thrombolysis 8(2): 143-150.

26. PRIMI trial study group (1989) Randomized double blind trial of recombinant pro-urokinase against streptokinase in acute myocardial infarction. Lancet 1(8643): 863-868.

27. Szarka SJ, Sihota EG, Habibi HR, Wong S (1999) Staphylokinase as a Plasminogen Activator component in Recombinant Fusion Proteins. Appl Environ Microbiol 65(2): 506-513.

28. Moise MA, Kashyap VS (2008) Alfimeprase for the treatment of acute peripheral arterial occlusion. Expert Opin Biol Ther 8(5): 683-689.

29. Weitz JI, Eikelboom JW, Samama MM (2012) New Antithrombotic drugs (Antithrombotic therapy and prevention of thrombosis, $\left(9^{\text {th }}\right.$ edn): American College of Chest Physicians Evidence-based clinical practice guidelines). Chest 141(2): e120S-e151S.

30. Hill MD, Menon BK (2015) Desmoteplase for late treatment of stroke: still in the dark. The Lancet Neurol 14(6): 560-561.

31. Curtis LD, Brown A, Comer MB, Senior JM, Warrington S, et al. (2005) Pharmacokinetics and pharmacodynamics of BB-10153, a thrombinactivatable plasminogen, in healthy volunteers. J Thromb Haemost 3(6): 1180-1186.

32. Gibson CM, Zorkun C, Molhoek P, Zmudka K, Greenberg M, et al. (2006) Dose escalation trial of the efficacy, safety, and pharmacokinetics of a novel fibrinolytic agent, BB-10153, in patients with ST elevation MI: results of the TIMI 31 trial . J Thromb Thrombolysis 22(1): 13-21.

\section{Your next submission with Juniper Publishers will reach you the below assets}

- Quality Editorial service

- Swift Peer Review

- Reprints availability

- E-prints Service

- Manuscript Podcast for convenient understanding

- Global attainment for your research

- Manuscript accessibility in different formats

( Pdf, E-pub, Full Text, Audio)

- Unceasing customer service

Track the below URL for one-step submission https://juniperpublishers.com/online-submission.php 